\title{
Streptococcus pneumoniae Invades Erythrocytes and Utilizes Them to Evade Human Innate Immunity
}

\author{
Masaya Yamaguchi ${ }^{1,2,3}$, Yutaka Terao ${ }^{2,4 *}$, Yuka Mori-Yamaguchi ${ }^{3}$, Hisanori Domon ${ }^{4}$, Yuuki Sakaue $^{4}$, \\ Tetsuya Yagi ${ }^{5}$, Kunihiko Nishino ${ }^{1}$, Akihito Yamaguchi ${ }^{1}$, Victor Nizet ${ }^{3}$, Shigetada Kawabata ${ }^{2}$
}

1 Department of Cell Membrane Biology, Institute of Scientific and Industrial Research, Osaka University, Ibaraki, Osaka, Japan, 2 Department of Oral and Molecular Microbiology, Osaka University Graduate School of Dentistry, Suita, Osaka, Japan, 3 Department of Pediatrics, University of California San Diego, La Jolla, California, United States of America, 4 Division of Microbiology and Infectious Diseases, Niigata University Graduate School of Medical and Dental Sciences, Chuo-ku, Niigata, Japan, $\mathbf{5}$ Center of National University Hospital for Infection Control, Nagoya University Hospital, Nagoya, Aichi, Japan

\begin{abstract}
Streptococcus pneumoniae, a Gram-positive bacterium, is a major cause of invasive infection-related diseases such as pneumonia and sepsis. In blood, erythrocytes are considered to be an important factor for bacterial growth, as they contain abundant nutrients. However, the relationship between S. pneumoniae and erythrocytes remains unclear. We analyzed interactions between S. pneumoniae and erythrocytes, and found that iron ion present in human erythrocytes supported the growth of Staphylococcus aureus, another major Gram-positive sepsis pathogen, while it partially inhibited pneumococcal growth by generating free radicals. S. pneumoniae cells incubated with human erythrocytes or blood were subjected to scanning electron and confocal fluorescence microscopic analyses, which showed that the bacterial cells adhered to and invaded human erythrocytes. In addition, S. pneumoniae cells were found associated with human erythrocytes in cultures of blood from patients with an invasive pneumococcal infection. Erythrocyte invasion assays indicated that LPXTG motifcontaining pneumococcal proteins, erythrocyte lipid rafts, and erythrocyte actin remodeling are all involved in the invasion mechanism. In a neutrophil killing assay, the viability of $S$. pneumoniae co-incubated with erythrocytes was higher than that without erythrocytes. Also, $\mathrm{H}_{2} \mathrm{O}_{2}$ killing of $\mathrm{S}$. pneumoniae was nearly completely ineffective in the presence of erythrocytes. These results indicate that even when $S$. pneumoniae organisms are partially killed by iron ion-induced free radicals, they can still invade erythrocytes. Furthermore, in the presence of erythrocytes, S. pneumoniae can more effectively evade antibiotics, neutrophil phagocytosis, and $\mathrm{H}_{2} \mathrm{O}_{2}$ killing.
\end{abstract}

Citation: Yamaguchi M, Terao Y, Mori-Yamaguchi Y, Domon H, Sakaue Y, et al. (2013) Streptococcus pneumoniae Invades Erythrocytes and Utilizes Them to Evade Human Innate Immunity. PLoS ONE 8(10): e77282. doi:10.1371/journal.pone.0077282

Editor: Daniel Paredes-Sabja, Universidad Andres Bello, Chile

Received May 24, 2013; Accepted August 31, 2013; Published October 23, 2013

Copyright: (c) 2013 Yamaguchi et al. This is an open-access article distributed under the terms of the Creative Commons Attribution License, which permits unrestricted use, distribution, and reproduction in any medium, provided the original author and source are credited.

Funding: This study was supported in part by a Grant-in-Aid for Scientific Research on Priority Areas from the Ministry of Education, Culture, Sports, Science and Technology of Japan, as well as Grants-in-Aid for Scientific Research (B), Young Scientists (A), and Challenging Exploratory Research from the Japan Society for the Promotion of Science (JSPS) and a Fellowship from JSPS. The funders had no role in study design, data collection and analysis, decision to publish, or preparation of the manuscript.

Competing Interests: The authors have declared that no competing interests exist.

*E-mail: terao@dent.niigata-u.ac.jp

\section{Introduction}

Severe community-acquired pneumonia reported to be the most common cause of death from infection in developed countries [1]. Streptococcus pneumoniae is a Gram-positive bacterium and the main cause of community acquired pneumonia worldwide. The pathogen is estimated to be responsible for the deaths of at least 800,000 children each year from pneumococcal disease [2]. In addition, antimicrobial resistance among $S$. pneumoniae strains is increasing throughout the world [3]. S. pneumoniae has been categorized into at least 91 serotypes based on the antigenic property of its capsule polysaccharide, while a capsule-conjugated vaccine against a subset of pneumococcal serotypes has shown considerable benefits [4]. However, it has also been reported that serotypes not targeted by the vaccine are increasing $[5,6]$, while another study showed that $S$. pneumoniae can adapt to clinical interventions over a remarkably short period of time because of a high rate of recombination [7].

S. pneumoniae has a variety of virulence factors that contribute to its ability to cause disease, including the secreted toxin pneumo- lysin (Ply) [8]. Ply is a member of the cholesterol-dependent cytolysin family, a large group of proteins that attack cholesterolcontaining membranes, which form ring-shaped pores and become localized in pneumococcal cell walls [9]. A peculiar property of $S$. pneumoniae is its tendency to spontaneously undergo autolysis, with the major autolysin an $\mathrm{N}$-acetyl-muramyl-L-alanine amidase termed LytA [10]. This autolysin degrades peptidoglycan in the pneumococcal cell wall, while it has also been reported that LytA-negative $S$. pneumoniae mutants showed reduced virulence in murine models of pneumonia and bacteraemia [8]. Pneumococcal sortase A is a member of a group of enzymes found in a variety of Gram-positive bacteria that mediate the covalent attachment of proteins containing an LPXTG motif to the cell wall [11]. Through cell wall anchoring of these proteins, sortase A contributes to adhesion to and invasion of human epithelial cells, as well as imparting protection against phagocytic clearance of Gram-positive pathogens including S. pneumoniae. Although various strategies for colonization of host epithelial surfaces have been elucidated, the behavior of $S$. pneumoniae in blood remains poorly understood. 
Erythrocytes, with a concentration of approximately $5 \times 10^{9}$ cells $/ \mathrm{ml}$, comprise $40-50 \%$ of blood volume, and are a key component for the transfer of oxygen and carbon dioxide for cellular respiration. Erythrocytes are also considered to be an important factor in regard to bacterial growth, as they contain abundant nutrients, especially iron, which is required for life in nearly all forms [12]. However, iron interacts with superoxide and hydrogen peroxide $\left(\mathrm{H}_{2} \mathrm{O}_{2}\right)$ to generate a highly reactive and extremely damaging hydroxyl radical [12]. In addition, a case of transfusion-transmitted S. pneumoniae infection caused by contaminated erythrocytes has been reported [13]. However, the relationship between $S$. pneumoniae and erythrocytes has received little attention.

In this study, we provide evidence for the first time that iron in erythrocytes partially inhibits pneumococcal growth using a freeradical-based mechanism, and also that $S$. pneumoniae is able to invade human erythrocytes. Furthermore, we present findings from a neutrophil bactericidal assay showing that the survival rate of $S$. pneumoniae in cultures with erythrocytes was increased by 3 fold as compared to those without erythrocytes. Our results reveal a previously unknown infection strategy employed by $S$. pneumoniae, and also suggest that evasion of the host immune system is facilitated by the pathogen's use of erythrocyte components and invading human erythrocytes during infection.

\section{Materials and Methods}

\section{Bacterial Strains and Reagents}

S. pneumoniae strain D39 (NCTG 7466) was purchased from the National Collection of Type Cultures. S. pneumoniae strain R6, which is an unencapsulated derivative D39, was kindly provided by Dr. Shin-ichi Yokota (Sapporo Medical University, Japan). $S$. pneumoniae ply-negative strain R6 and lytA-negative mutant strain R6 have been described [14,15]. Inactivation of the srtA gene by double crossover recombination was performed as previously reported $[14,16]$. The primers used are shown in Table 1. S. pneumoniae and $S$. aureus were grown in Tryptic Soy broth (Becton Dickinson, USA) or 5\% sheep blood-Tryptic Soy agar plates with spectinomycin $(500 \mu \mathrm{g} / \mathrm{ml})$ added to the medium for mutant strain selection, while Escherichia coli strain XL-10 Gold (Stratagene, USA) was grown in Luria-Bertani broth (Sigma, USA) or on Luria-Bertani agar plates, supplemented with $100 \mu \mathrm{g} / \mathrm{ml}$ of ampicillin or spectinomycin.

Table 1. PCR primers used in this study.

\begin{tabular}{|c|c|c|}
\hline Designation & Sequence $\left(5^{\prime}\right.$ to $\left.3^{\prime}\right)$ & Reference \\
\hline srtAu EcoF & GAATTCTGGATCAGGACGAGTTCACTGC & This study \\
\hline srtAu BamR & GGATCCCATTATGCTTCACCTTCTGTTTCG & This study \\
\hline srtAd XbaF & TCTAGATAATACAAATCAGTGAAATCAT & This study \\
\hline srtAd HindR & AAGCTTCAGTGGCGAAGCATATTTCCAAC & This study \\
\hline PlyKOu EcoF & GAATTCGTAGCTCTTTATTTGCCTITTCC & [14] \\
\hline PlyKOu BamR & GGATCCTCGATAACAACAAACTCATCGG & [14] \\
\hline PlyKOd XbaF & TCTAGAGGACAATACAGAAGTGAAGGC & [14] \\
\hline PlyKOd HindR & AAGCTTCTAGTCATTTTCTACCTTA & {$[14]$} \\
\hline lytAs KpnF & GGGGTACCGTCTGGGGTGTTATTGTAGATAG & {$[15]$} \\
\hline lytAs BamR & CGGGATCCCCTGCTTCATCTGCTAGATTGCG & {$[15]$} \\
\hline lytAi XbaF & GCTCTAGAGCCGAAAACGCTTGATACAGGG & {$[15]$} \\
\hline lytAi PstR & AACTGCAGCCGTCTGGTTTGAGGTAGTACCAGCC & [15] \\
\hline
\end{tabular}

\section{Isolation of Human Neutrophils and Erythrocytes}

Neutrophils were prepared as previously described [14,17]. Briefly, $10 \mathrm{ml}$ of heparinized blood was obtained from healthy donors and mixed 1:1 with phosphate buffered saline containing $3 \%$ dextran T500. After incubation at room temperature for $60 \mathrm{~min}$, the supernatant was layered on Ficoll-Paque (GE Healthcare, USA). After centrifugation at $450 \times \mathrm{g}$ for $20 \mathrm{~min}$, layers containing erythrocytes and neutrophils were collected. Residual erythrocytes were lysed by hypotonic shock, and then the cells were suspended in RPMI 1640. Cell viability was monitored using the trypan blue exclusion technique and cells were counted with a hemocytometer. Fresh normal erythrocytes were obtained by drawing heparinized blood from volunteer donors, then washed 3 times in RPMI 1640 to remove the buffy coat and used as required.

\section{Assays of Growth with Erythrocytes}

Growth of $S$. pneumoniae strain R6, D39 and S. aureus strain Cowan I with erythrocytes and erythrocyte lysates was determined by counting viable CFU. Erythrocytes were suspended to $5.0 \times 10^{9}$ cells/ml in RPMI 1640. Bacterial cells $\left(\sim 1.0 \times 10^{2} \mathrm{CFU} /\right.$ well $)$ were added to erythrocytes with or without a final mixture of $1 \mathrm{mM}$ 2,2'-bipyridyl (Sigma), $1 \mathrm{mM}$ 2-ethyl-2-thiopseudourea, hydrobromide (S-Ethyl-ITU, Calbiochem, Germany), $100 \mu \mathrm{M}$ EUK-8 (Calbiochem), or $150 \mu \mathrm{M}$ MnTBAP (Calbiochem) for 2, 4 , or 6 hours at $37^{\circ} \mathrm{C}$ in $5 \% \mathrm{CO}_{2}$. In a growth assay using hemoglobin $(\mathrm{Hb})$, bacterial cells $\left(\sim 1.0 \times 10^{2} \mathrm{CFU} /\right.$ well $)$ were incubated with or without a final mixture of $10 \mathrm{mg} / \mathrm{ml}$

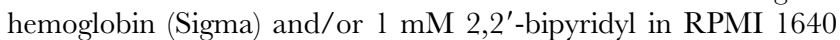
for 2,4 , or 6 hours at $37^{\circ} \mathrm{C}$ in $5 \% \mathrm{CO}_{2}$. The concentrations of these inhibitors were previously shown to prevent or minimize reactions [18,19,20,21,22]. The mixtures were serially diluted and plated in TS blood agar. Following incubation, CFU values were determined.

Erythrocyte lysates were prepared using a sonicator. Erythrocytes were suspended to $5.0 \times 10^{9}$ cells $/ \mathrm{ml}$ in RPMI 1640 and sonicated for 10 minutes on ice. To remove disrupted cell membrane debris, the mixture was centrifuged and the supernatant passed through a $0.20-\mu \mathrm{m}$ filter. Lysates after filtering were used as membrane-free preparations, while sonicated erythrocytes were used as the membrane-containing counterpart.

\section{Confocal Fluorescence Microscopic Analysis}

Confocal microscopic analysis was performed as previously described [14,17]. Briefly, fresh erythrocytes $\left(1 \times 10^{7}\right.$ cells $)$ were infected with $S$. pneumoniae strain R6 or D39 $\left(2.5 \times 10^{5} \mathrm{CFU}\right)$ for 1 hour, then fixed with $2 \%$ glutaraldehyde-RPMI 1640 . To observe the localization of $S$. pneumoniae, the bacterial cells were stained with SYTOX Green and erythrocytes were visualized using Alexa Fluor 594 phalloidin (Life Technology, USA). Stained bacteria and erythrocytes were observed using an LSM 510 confocal laser scanning microscope equipped with an $\alpha$ Plan-fluor $100 \times / 1.45$ oil objective lens or a BZ-9000 fluorescent microscopic analyzing system (Keyence, Japan). The obtained images were analyzed with LSM 510 software, version 3.2 SP2 (Carl Zeiss, Germany).

\section{Scanning Electron Microscopic Analysis}

Strains R6 and D39 $\left(2.5 \times 10^{6} \mathrm{CFU}\right)$ was mixed separately with fresh human blood samples $(2 \mathrm{ml})$ and incubated at $37^{\circ} \mathrm{C}$ for 30 minutes, then fixed with $2 \%$ glutaraldehyde-RPMI 1640 for 1 hour at room temperature and washed with distilled water, after which the samples were dehydrated with $100 \% t$-butyl alcohol and 
freeze-dried. Finally, the samples were coated with platinum and examined using an emission-SEM (JSM-6390LVZ with SEM control user interface software version 8.16; JEOL Ltd., Japan).

\section{Erythrocyte Invasion Assay}

The bactericidal invasion of human erythrocytes was quantified using standard procedures with minor modifications, as previously described $[16,23]$. Briefly, erythrocytes were pretreated with or without $5 \mathrm{mM}$ metyl- $\beta$-cyclodextrin $(\mathrm{M} \beta \mathrm{CD})$ or $20 \mu \mathrm{M}$ cytochalasin $\mathrm{D}$ for 30 minutes at $4^{\circ} \mathrm{C}$, then used for examinations after washing twice. M $\beta$ CD is able to disrupt lipid rafts by depleting cholesterol $[24,25]$. Erythrocytes were added to 96 -well plates at a density of $5 \times 10^{7}$ cells per well and infected with $1 \times 10^{4} \mathrm{CFU}$ of bacteria per well (multiplicity of infection, 1:5000) for 1 hour. To quantify bacterial invasion, cells incubated with $S$. pneumoniae for 1 hour were washed 3 times and incubated for 1 hour in RPMI 1640 medium containing penicillin $\mathrm{G}(100 \mathrm{units} / \mathrm{ml})$, then washed again, lysed, and plated to determine the number of invaded S. pneumoniae organisms.

\section{Animal Infection}

S. pneumoniae strain D39 was infected directly into the lungs of mice using a high-pressure syringe Model FMJ-250 with a MicroSprayer Model IA-1C (Penn-Century, Inc., USA) inserted into the trachea. To reduce damage to the lungs by liquid, the organisms $\left(2.5 \times 10^{7} \mathrm{CFU}\right.$ per mouse $)$ were infected as an aerosol using a high-pressure syringe. Three days after infection, mice were euthanized, then the lungs were collected and stained with hematoxylin and eosin (HE) for microscopic examinations. At least 10 microscopic fields (1,000-fold magnification) in the lungs of each mouse $(\mathrm{n}=3)$ were observed and the numbers of bacteria associated with erythrocytes were counted.

\section{Neutrophil Killing Assay}

S. pneumoniae strain R6 or D39 was grown to the mid-log phase and resuspended in RPMI1640. Next, $10 \mu \mathrm{l}$ of bacteria (R6:2.2 $\times 10^{2}$ CFU, D39:1.4 × $\left.10^{2} \mathrm{CFU}\right)$ was combined with $90 \mu \mathrm{l}$ of fresh human neutrophils $\left(1.0 \times 10^{5}\right.$ cells $)$ with or without erythrocytes $\left(5.0 \times 10^{7}\right.$ cells $)$, and/or $10 \%$ human blood serum or heat-inactivated human blood serum, then the mixtures were incubated while being rotated at $37^{\circ} \mathrm{C}$ for 1 , 2, or 3 hours. Viable cell counts were determined by plating lysed and diluted samples onto blood agar.

\section{$\mathrm{H}_{2} \mathrm{O}_{2}$ Killing Assay}

S. pneumoniae strain R6 or D39 was grown to the mid-log phase and resuspended in RPMI 1640. Next, $1.0 \times 10^{2} \mathrm{CFU} / 10 \mu \mathrm{l}$ of bacteria was incubated with or without erythrocytes $\left(5.0 \times 10^{6}\right.$ or $5.0 \times 10^{8}$ cells $/ 90 \mu \mathrm{l}$ ) for 30 minutes, then $\mathrm{H}_{2} \mathrm{O}_{2}$ was added (final concentration $0 \%, 0.03 \%$; $8.82 \mathrm{mM}$, or $0.30 \%$; $88.2 \mathrm{mM}$ ). Viable cell counts were determined by plating diluted samples onto blood agar following 30 minutes of incubation.

\section{Ethics Statement}

All mice experiments were conducted in accordance with animal protocols approved by the Animal Care and Use Committees at Osaka University Graduate School of Dentistry. Blood was obtained via venopuncture from healthy Japanese volunteers under written informed consent according to a protocol approved by the institutional review boards of Osaka University Graduate School of Dentistry, Niigata University Graduate School of Medical and Dental Sciences, and the University of California San Diego. Blood cultures from the patients were obtained after they had given written informed consent according to a protocol approved by the Nagoya University Hospital Ethics Review Board.

\section{Results}

\section{Iron Inhibits Growth of S. pneumoniae with Human Erythrocytes}

We speculated that erythrocytes contribute to the proliferation of $S$. pneumoniae and examined their role in pneumococcal growth. Approximately 50 colony forming units (CFU) of $S$. pneumoniae strain R6, D39, or $S$. aureus strain Cowan I were prepared with erythrocytes, then the mixtures were cultured with or without an iron chelator, $2,2^{\prime}$-bipyridyl, at $37^{\circ} \mathrm{C}$. Next,

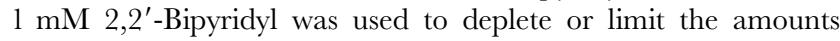
of iron ion [18]. Bacterial growth was determined by counting the number of viable $\mathrm{CFU}$ on blood agar. We found that addition of the iron chelator inhibited the growth of $S$. aureus with erythrocytes (Fig. 1) and chelator-treated $S$. aureus did not grow on Tryptic Soy agar (data not shown). This finding is consistent with previous reports, which noted that iron is essential for $S$. aureus [26] and its growth in the presence of erythrocytes was significantly inhibited by an iron chelator [18]. In contrast, we found that the growth of $S$. pneumoniae was significantly enhanced by 54-, 69-, and 173-fold (R6), or 2.0-, 2.3-, and 8.3- fold (D39) when cultured in the presence of the iron chelator for 2, 4, and 6 hours, respectively (Fig. 1A). Next, we cultured both bacterial strains with erythrocyte lysates. The growth of $S$. aureus grown with erythrocyte lysates was similar to that when incubated with intact erythrocyte cells, while a lower level of growth inhibition of $S$. pneumoniae was seen when grown with erythrocyte lysates as compared to intact erythrocyte cells (Fig. 1B). The bacterial growth activity of $S$. pneumoniae with erythrocyte lysates and the iron chelator was increased by 2.4-, 3.4-, and 2.2-fold (R6), or 1.1-, 1.4-, and 1.3- fold (D39) after 2, 4 , and 6 hours, respectively, as compared to without the chelator. In contrast, addition of the iron chelator did not have a significant effect on the growth of $S$. pneumoniae strains R6 and D39 when cultured in RPMI 1640 medium without erythrocytes (Fig. 1C). These results indicate that $S$. pneumoniae does not require a rich iron ion environment in comparison to $S$. aureus, and instead that iron ions inhibit $S$. pneumoniae growth.

\section{Erythrocytes Inhibit Growth of S. pneumoniae via Iron- induced Free Radical-based Mechanism}

We next investigated whether erythrocyte iron ions inhibit pneumococcal growth. In the presence of $\mathrm{Hb}$, pneumococcal growth was not inhibited but rather increased as compared to without $\mathrm{Hb}$ (Fig. 2A). Next, we compared pneumococcal growth in the presence of erythrocyte lysates containing or lacking the erythrocyte membrane. When cultured with lysates with the membrane, growth was significantly inhibited in comparison to that observed in lysates without the membrane. In addition, the iron chelator diminished the degree of growth inhibition by lysates containing the erythrocyte membrane (Fig. 2B). These results indicate that pneumococcal growth inhibition requires both iron ions and the erythrocyte membrane.

Although iron is essential for the growth of a large proportion of bacteria, iron ions mediate the generation of free radicals [12,27], while superoxide anion, hydroxyl radical, and nitric oxide are generated in human erythrocyte free radical metabolism pathways [28]. A number of different electron transport processes are present in the erythrocyte membrane, and previous reports have shown that some of these electron transport chains function as 
A S. pneumoniae R6 + RBC

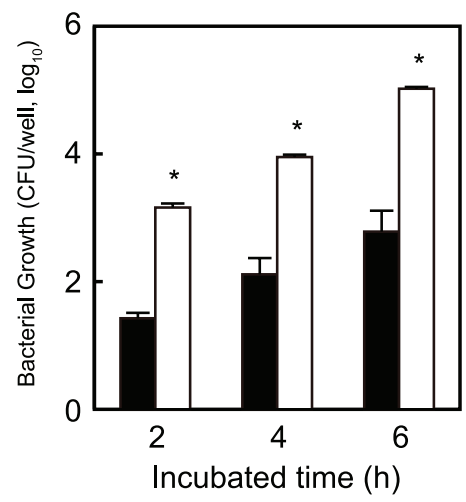

B

S. pneumoniae R6 + RBC lysate

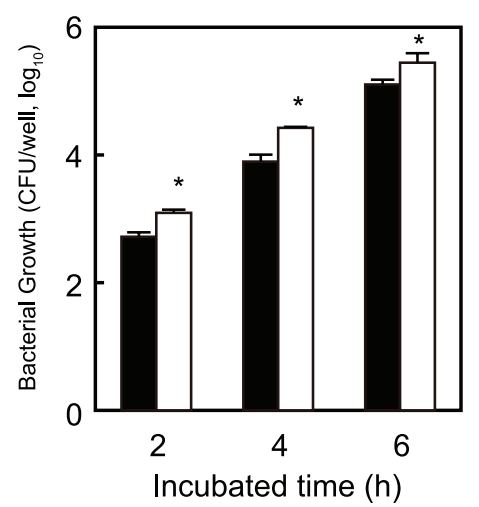

C S. pneumoniae R6 in RPMI 1640

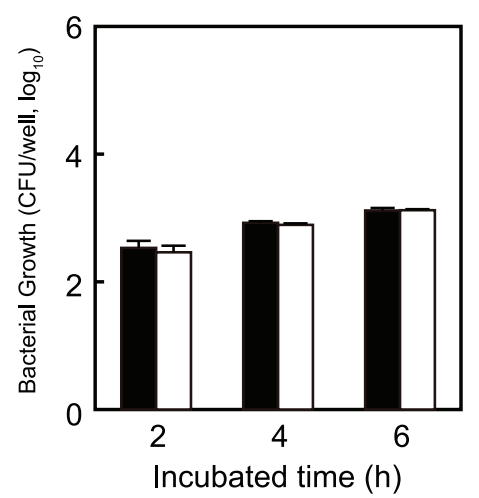

S. pneumoniae $\mathrm{D} 39+\mathrm{RBC}$

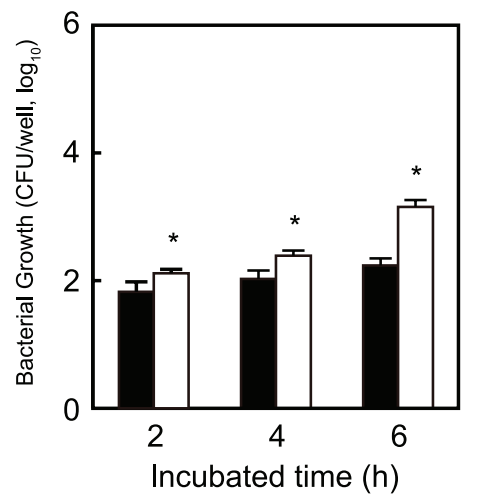

S. pneumoniae D39 + RBC lysate

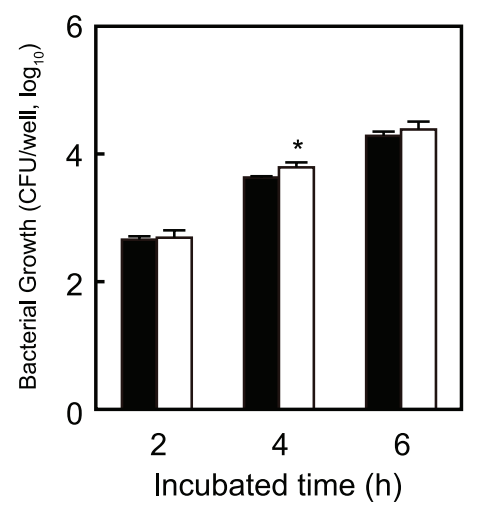

S. pneumoniae D39 in RPMI 1640

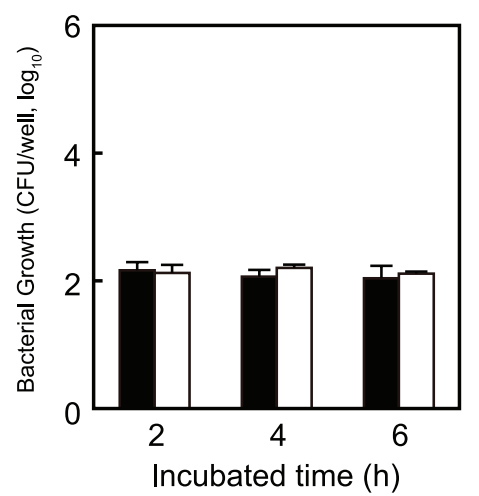

S. aureus + RBC

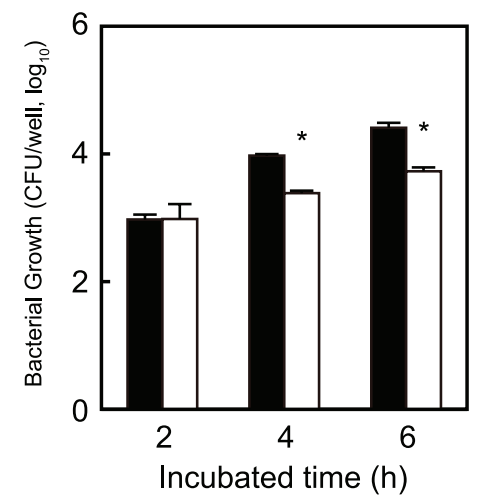

S. aureus + RBC lysate

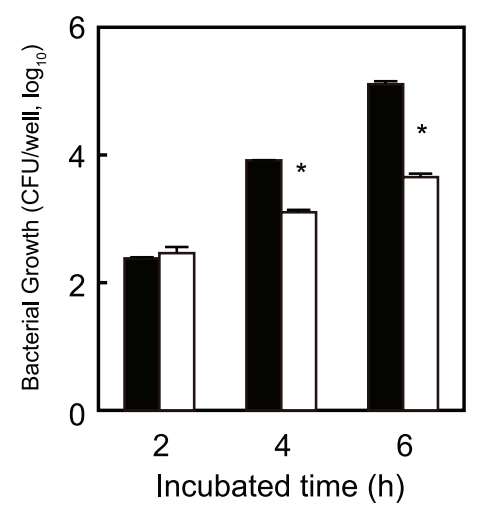

S. aureus in RPMI 1640

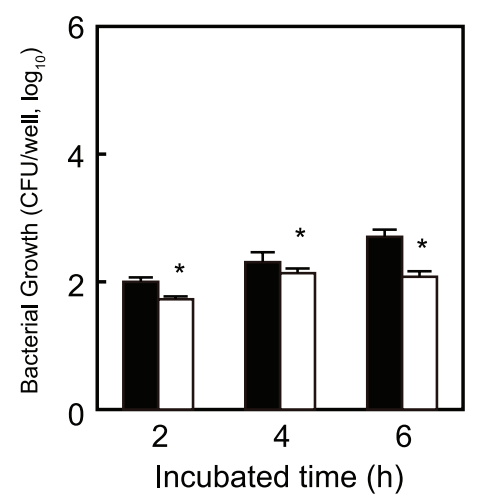

Fe chelator (-)

Fe chelator $(+)$

Figure 1. Effects of erythrocytes and iron ions on S. pneumoniae growth. A. Growth of S. pneumoniae strains R6 and D39, and S. aureus strain Cowan-I in the presence of human erythrocytes with or without an iron chelator. Bacterial cells were incubated for 2,4 , and 6 hours at $37^{\circ} \mathrm{C}$ in a $5 \%$ $\mathrm{CO}_{2}$ atmosphere. B. Growth of S. pneumoniae strains R6 and D39, and S. aureus strain Cowan-l in erythrocyte intracellular solution (erythrocyte lysates without membrane) with or without an iron chelator for 2,4 , and 6 hours at $37^{\circ} \mathrm{C}$ in a $5 \% \mathrm{CO}_{2}$ atmosphere. C. Growth of S. pneumoniae strains R6 and D39, and S. aureus strain Cowan-I in RPMI 1640 medium with or without an iron chelator for 2,4 , and 6 hours at $37^{\circ} \mathrm{C}$ in a $5 \% \mathrm{CO}_{2}$ atmosphere. The experiments were performed 3 times and data shown represent the mean of 3 wells from a representative experiment. S.D. values are represented by vertical lines.

doi:10.1371/journal.pone.0077282.g001 


\section{A}

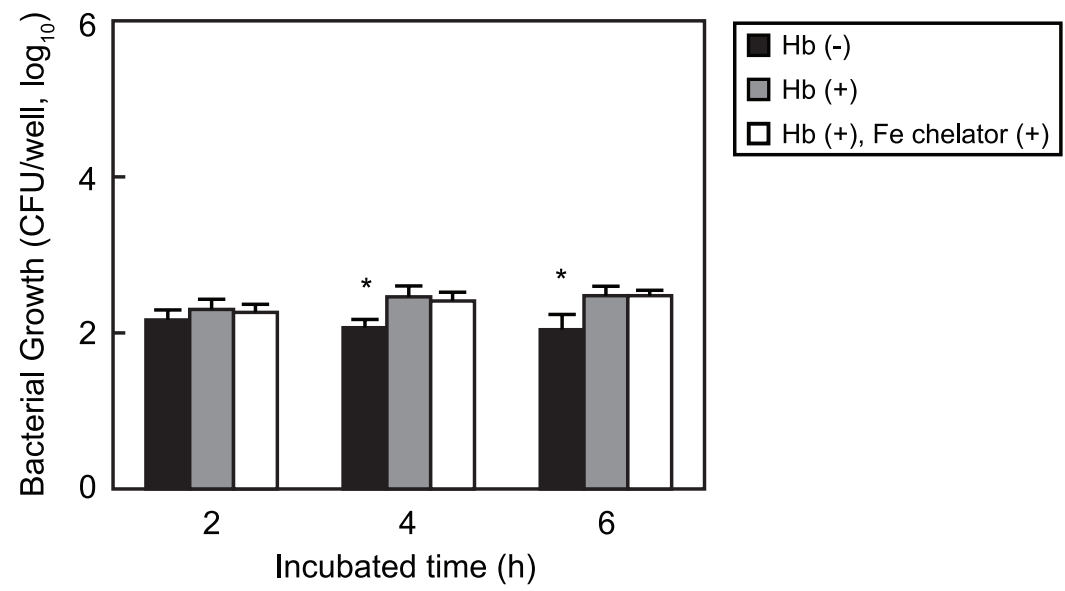

B
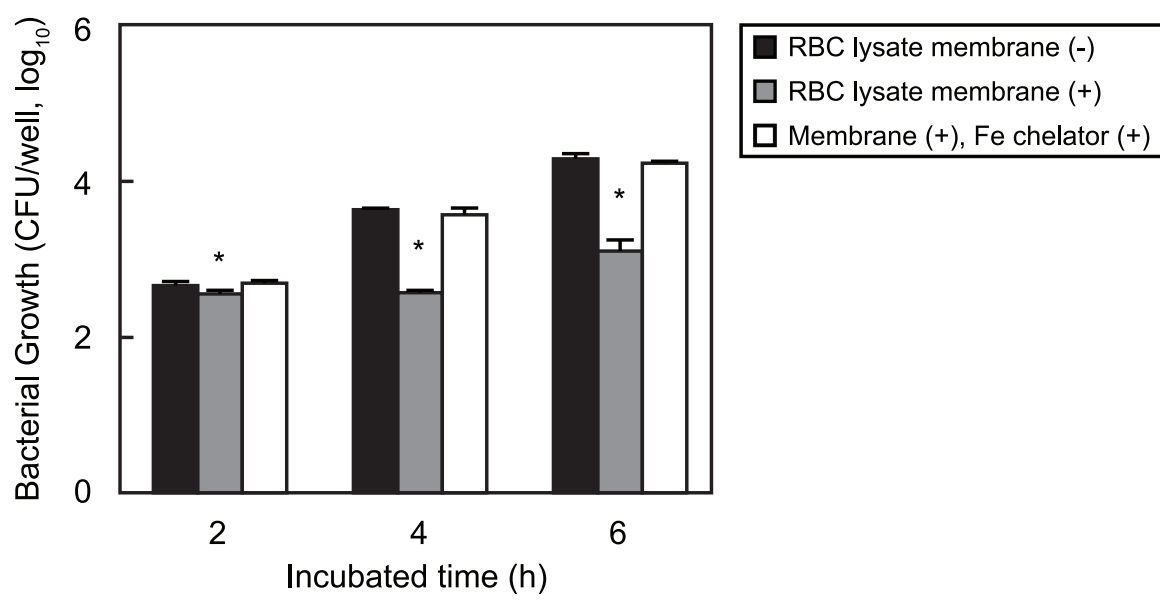

Figure 2. Erythrocyte intracellular solution inhibits pneumococcal growth in presence of erythrocytes with the membrane. $A$. Growth of S. pneumoniae strain D39 in RPMI 1640 medium with or without human hemoglobin and/or an iron chelator for 2,4 , and 6 hours at $37^{\circ} \mathrm{C}$ in a $5 \%$ $\mathrm{CO}_{2}$ atmosphere. $B$. Growth of $S$. pneumoniae strain D39 in erythrocyte lysates with or without the erythrocyte membrane and/or an iron chelator for 2,4 , and 6 hours at $37^{\circ} \mathrm{C}$ in a $5 \% \mathrm{CO}_{2}$ atmosphere. The experiments were performed 3 times and data shown represent the mean of 3 wells from a representative experiment. S.D. values are represented by vertical lines. doi:10.1371/journal.pone.0077282.g002

electron donors and can generate superoxide anion [28,29]. We speculated that free radicals would inhibit the growth of $S$. pneumoniae when grown with erythrocytes and examined the mechanism of pneumococcal growth inhibition using oxidative stress inhibitors. S. pneumoniae was incubated with erythrocytes in the presence of an iron chelator (2,2'-bipyridyl), nitric oxide synthase inhibitor (S-Ethyl-ITU), free radical scavenger (EUK-8), or superoxide dismutase mimetic (MnTBAP) for 2 hours. S-EthylITU is an inhibitor of all isoforms of nitric oxide synthases [19], while EUK-8 has high superoxide dismutase- and catalase-mimic activities, and oxyradical scavenging activities [20], and MnTBAP functions as a superoxide dismutase mimetic but does not scavenge nitric oxide $[21,22]$. Each mixture was plated on tryptic soy blood agar, and the increase in number of $S$. pneumoniae $\mathrm{CFU}$ recovered was determined. The growth rates of $S$. pneumoniae when incubated with the iron chelator, free radical scavenger, and superoxide dismutase mimetic were at least 11-fold (R6) or 1.5-fold (D39) greater than that of $S$. pneumoniae grown with S-Ethyl-ITU or without inhibitors (Fig. 3). Based on these results, we concluded that erythrocytes inhibit pneumococcal growth via a free radicalbased mechanism.

\section{S. pneumoniae Invades Human Erythrocytes}

Gram staining of blood cultures infected with invasive S. pneumoniae bacteria under clinical laboratory test conditions showed that some of the pneumococci became associated with human erythrocytes (Fig. 4A). In order to further investigate the invasion of erythrocytes by $S$. pneumoniae, mixtures of the bacteria and erythrocytes were analyzed in detail using a scanning electron microscope (SEM) and confocal fluorescence microscopy. SEM analysis was performed with human blood samples incubated for 1 hour with unencapsulated S. pneumoniae strain R6 or its encapsulated parent strain D39 (Fig. 4B), which revealed that the organisms adhered to (Fig. $4 B a, c$ ) and invaded (Fig. $4 B b, d$ ) erythrocytes in human blood, regardless of the capsule phenotype. In fluorescence analysis with confocal microscopy performed with 

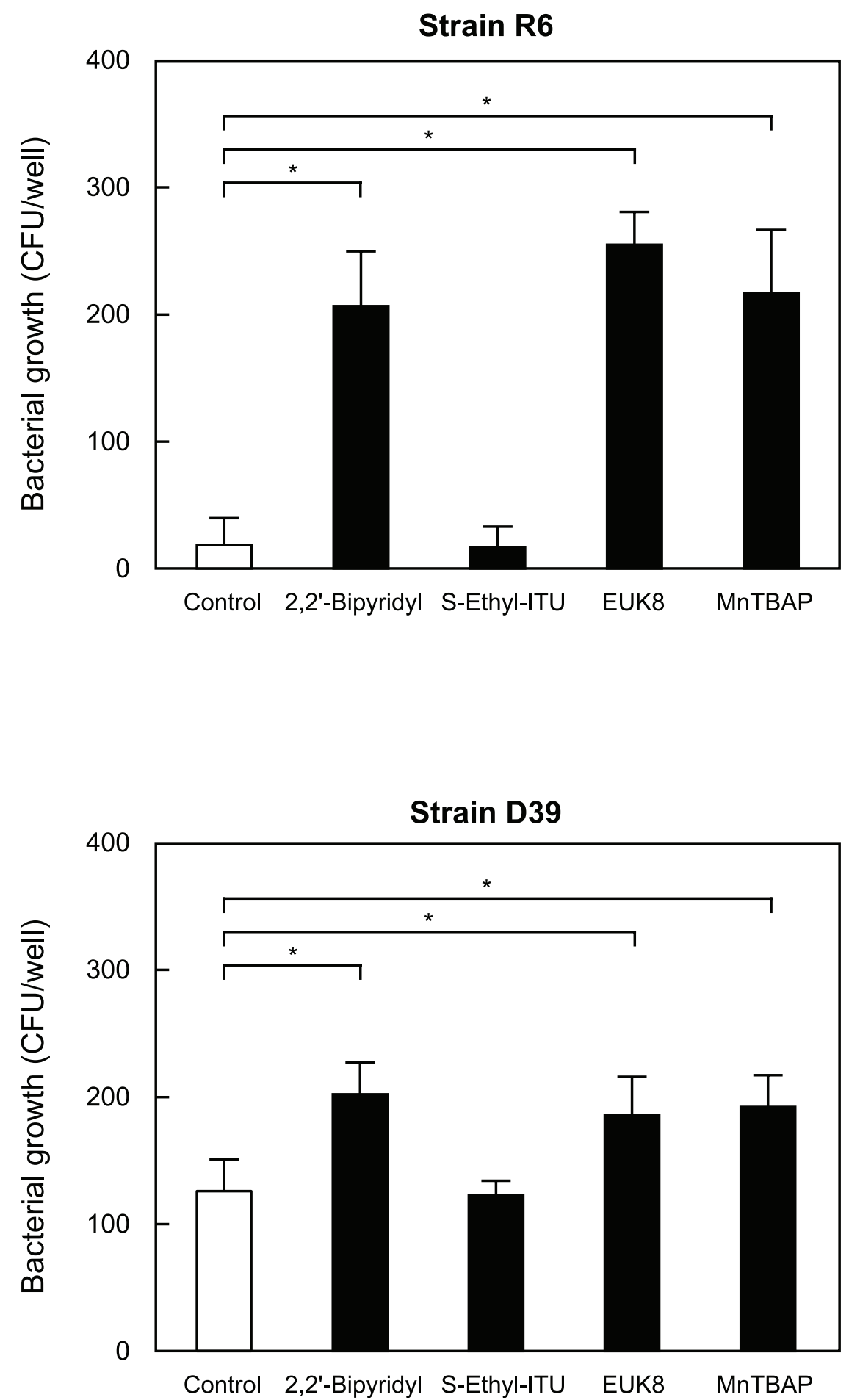

Figure 3. Erythrocytes inhibit pneumococcal growth by reactive oxygen species-related mechanism. S. pneumoniae cells $\left(\sim 1 \times 10^{2} \mathrm{CFU}\right.$, $10 \mu \mathrm{l}$ ) were added to erythrocytes $\left(5 \times 10^{9} \mathrm{cells} / \mathrm{ml}, 190 \mu \mathrm{l}\right)$ with or without $1 \mathrm{mM} 2,2^{\prime}$-bipyridyl (iron chelator), 1 mM S-ethyl-ITU (nitric oxide synthase inhibitor), $100 \mu \mathrm{M}$ EUK8 (synthetic catalytic free radical scavenger), or $150 \mu \mathrm{M}$ MnTBAP (superoxide dismutase mimetic) for 2 hours at $37^{\circ} \mathrm{C}$ in a $5 \%$ $\mathrm{CO}_{2}$ atmosphere. Next, each mixture was serially diluted and plated on TS blood agar. Following incubation, $\mathrm{CFU}$ values were determined. *Significant difference $(P<0.005)$ between mean values, as determined with a Mann-Whitney $U$-test. The experiments were performed 3 times and data are shown as the mean of 6 wells from a representative experiment. S.D. values are represented by vertical lines. doi:10.1371/journal.pone.0077282.g003

human erythrocytes incubated for 1 hour with $S$. pneumoniae strain R6 or D39 Z-stack analysis clearly showed that both strains invaded erythrocytes (Fig. 4C).
Next, we performed pneumococcal invasion assays to determine the percentages of intracellular bacteria in the early to late growth phases of $S$. pneumoniae. We added S. pneumoniae strain R6 or D39 $\left(\sim 1.0 \times 10^{4} \mathrm{CFU}\right)$ in each phase of growth to erythrocytes, and 
A

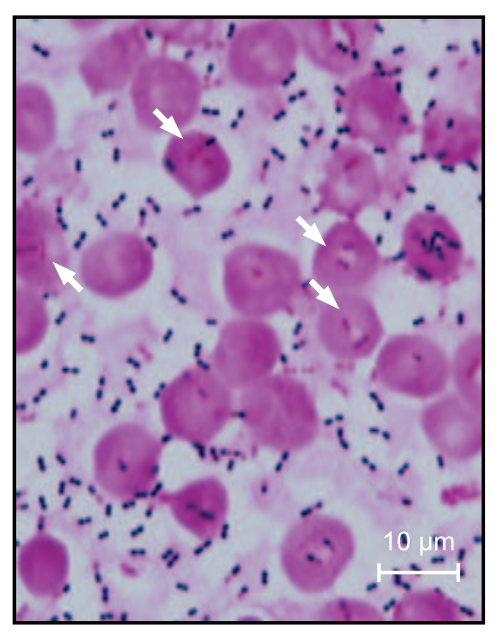

B
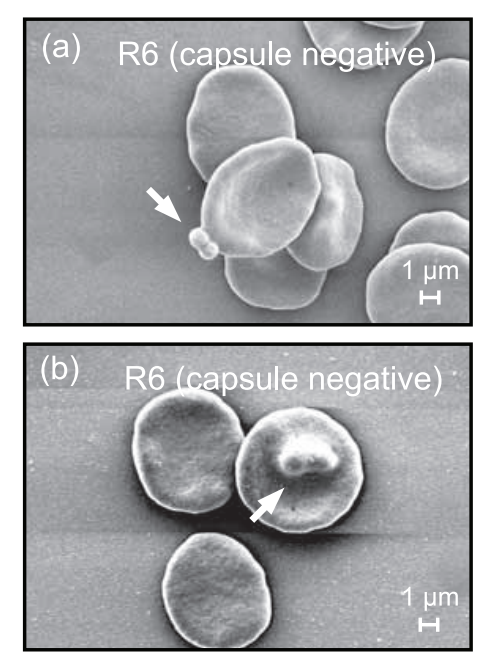

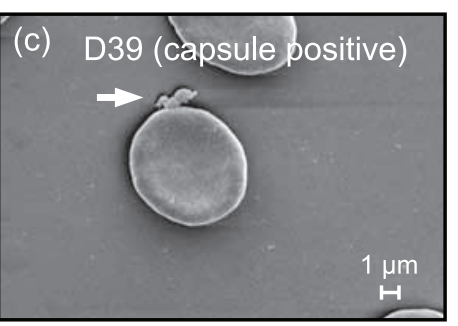

(d) D39 (capsule positive)

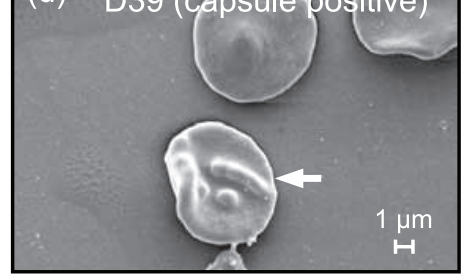

C
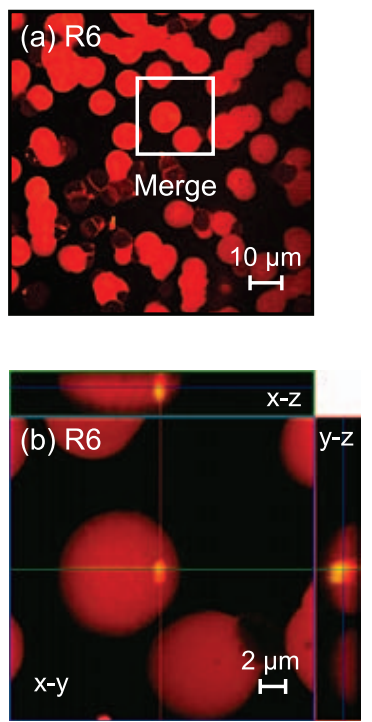
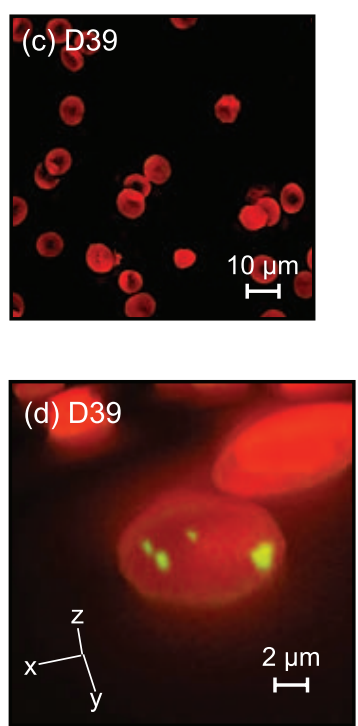

D

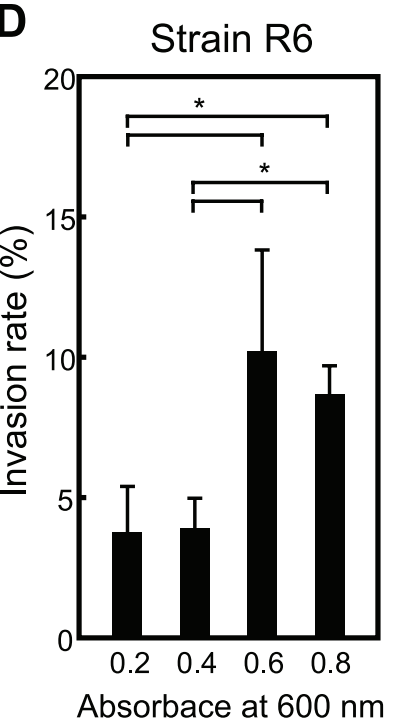

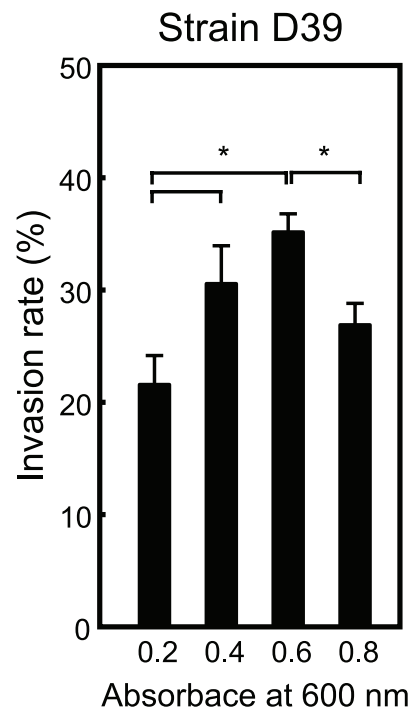

E
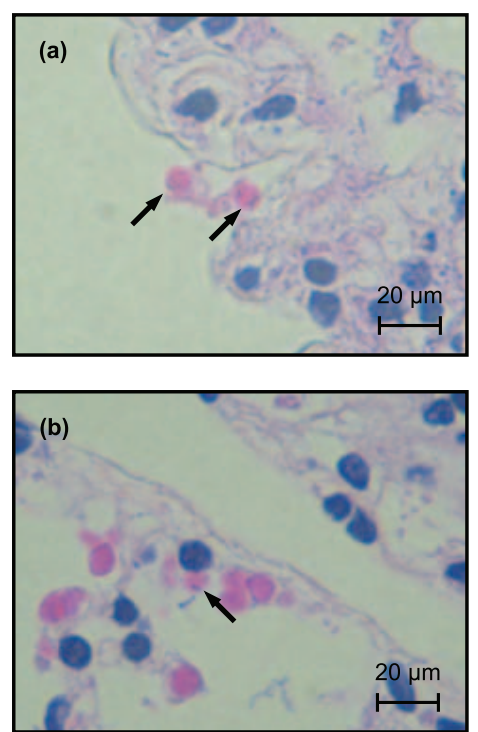

(c)

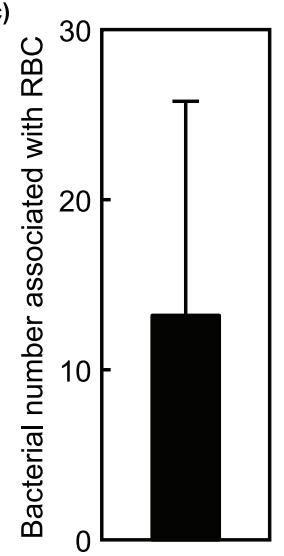

Figure 4. S. pneumoniae invasion of human erythrocytes. A. Gram staining of cultures of blood obtained from a patient with invasive pneumococcal pneumonia. A blood sample was obtained from a splenectomized patient with pneumococcal bacteremia and meningitis. We 
observed that some of the S. pneumoniae cells in the sample adhered to or invaded erythrocytes. B. SEM analysis of S. pneumoniae in blood. S. pneumoniae cells (arrows) were incubated in human whole blood for 30 minutes at $37^{\circ} \mathrm{C}$. Strains R6 and D39 adhered to (a, c) and invaded (b, d) erythrocytes in human blood. C. Confocal fluorescence microscopic analysis of S. pneumoniae strains R6 (a, b) and D39 (c, d) incubated with human erythrocytes for 30 minutes at $37^{\circ} \mathrm{C}$. (a, c) Erythrocytes were visualized using Alexa Fluor 594 Phalloidin. S. pneumoniae organisms were stained using SYTOX green. (b) Boxed areas from panel (a), along with $x-z$ and $y-z$ projections. (d) 3D analysis of image from panel (c) showing erythrocytes invaded by S. pneumoniae. D. Rate of S. pneumoniae invasion of erythrocytes. The numbers of invaded bacteria were determined as described in the Experimental Procedures section. *Significant difference $(P<0.005)$ between mean values, as determined with a Mann-Whitney $U$-test. The experiments were performed 3 times and data are shown as the mean of 6 wells from a representative experiment. S.D. values are represented by vertical lines. E. Histopathological examinations of infected mice lung tissues. Tissues were excised from sites of infection after 72 hours, then fixed, embedded in paraffin, and stained with hematoxylin-eosin solution. (a) and (b) were obtained from individual mice. Arrows indicate association of S. pneumoniae with erythrocytes. (c) Numbers of bacteria associated with erythrocytes per field. Data shown represent the mean of 10 fields from a representative mouse. S.D. values are represented by vertical lines. doi:10.1371/journal.pone.0077282.g004

found that the invasion rates of $\mathrm{R} 6$ were $3.8 \%, 3.9 \%, 10.2 \%$, and $8.7 \%$, while those of D39 were $21.6 \%, 30.6 \%, 35.2 \%$, and $26.9 \%$ at an absorbance $(600 \mathrm{~nm})$ of $0.2,0.4,0.6$, and 0.8 , respectively (Fig. 4D). These results indicated a significant difference for the invasion rate of $S$. pneumoniae between the early and late growth phases. In addition, S. pneumoniae grown with erythrocytes evaded antibiotic killing by invading those erythrocytes.

We also observed the interaction between $S$. pneumoniae and erythrocytes in vivo in lungs obtained from infected mice. For these studies, we used encapsulated strain D39, since non-encapsulated strain R6 is rapidly eliminated by the immune system of the mice. $S$. pneumoniae were injected in an intratracheal manner into C57BL/6 mice, then the lungs were obtained after euthanasia and stained with HE. Microscopic examinations revealed that $S$. pneumoniae organisms were associated with or had invaded erythrocytes in the lungs (Fig. $4 E$ ).

\section{S. pneumoniae Invade RBC via Actin-remodeling and Lipid Rafts}

Gram-positive bacteria invade host epithelial and endothelial cells via actin-remodeling caused by interactions between bacterial cell wall anchoring proteins and host receptors [30]. The cholesterol-dependent cytolysin of $S$. pneumoniae, termed Ply, was previously shown to cause cholesterol-dependent actin remodeling in SH-SY5Y human neuroblastoma cells [31]. In addition, lipid rafts, a cholesterol- and sphingolipid-enriched micro-domain in cell membranes, play crucial roles in the invasion of host cells by various pathogens [32]. To determine the invasion mechanisms, we performed invasion assays using several inhibitors and $S$. pneumoniae gene-deficient strains. We prepared $S$. pneumoniae strains at an absorbance $(600 \mathrm{~nm})$ of $0.6-0.7$. The $S$. pneumoniae $\Delta l y t A$ strain showed an invasion rate 3.0 -fold greater as compared to the wild-type strain, while the $\Delta s r t A$ strain showed a $61 \%$ reduction in invasion efficiency. Furthermore, encapsulated $S$. pneumoniae strain D39 showed an invasion frequency 2.5-fold greater compared to its unencapsulated derivative strain R6. On the other hand, no significant difference between the $\Delta p l y$ and the wild-type strains (Fig. 5). Lipid raft disruption of erythrocytes using the cholesterolextracting agent M $3 \mathrm{CD}$ resulted in a 64\% (R6) and 34\% (D39) reduction in invasion efficiency for the wild-type pneumococcal strains. In addition, inhibition of erythrocyte actin polymerization by cytochalasin D resulted in 2-fold drop in invasion efficiency for the wild-type R6 strain. In contrast, cytochalasin D did not inhibit invasion by strain D39. As for the $\Delta s r t A$ strain, lipid raft disruption and inhibition of actin polymerization resulted in invasion efficiencies of $28 \%$ and $77 \%$ of control, respectively. These results indicated that an LPXTG motif containing proteins, lipid rafts, and actin remodeling are all involved in the erythrocyte invasion pathway of $S$. pneumoniae.

\section{S. pneumoniae Evades Neutrophil Killing in the Presence of Erythrocytes}

We performed bactericidal assays to determine whether erythrocytes have effects on neutrophil bacterial killing. $S$. pneumoniae cells and neutrophils were incubated with or without erythrocytes in fresh or heat-inactivated human serum, then antiphagocytic activities were determined based on the viability of the $S$. pneumoniae organisms. In the absence of serum, the viability of $S$. pneumoniae with erythrocytes was higher than that without erythrocytes after 3 hours. In contrast, in the presence of fresh serum, recovery of viable $S$. pneumoniae strain R6 cells grown without erythrocytes declined gradually over a 1 to 3 hour time frame., In contrast, when the assay was performed in the presence of erythrocytes CFU recovery of pneumococci was significantly higher at the late time point. Parallel assays performed with strain D39 revealed a similar pattern. In the presence of heat-inactivated serum, the viability of $S$. pneumoniae strain R6 was not significantly changed (Fig. 6A). These results indicate that $S$. pneumoniae evades neutrophil opsonophagocytosis in the presence of erythrocytes.

Generation of $\mathrm{H}_{2} \mathrm{O}_{2}$ is one of the antimicrobial mechanisms of neutrophils. In addition, $S$. pneumoniae dies by exposure to its own production of $\mathrm{H}_{2} \mathrm{O}_{2}$ in a stationary phase [33]. For these reasons, we assessed the effect of erythrocytes on $S$. pneumoniae susceptibility to $\mathrm{H}_{2} \mathrm{O}_{2}$. We exposed $S$. pneumoniae strains $\mathrm{R} 6$ and D39 to a range of $\mathrm{H}_{2} \mathrm{O}_{2}$ concentrations in RPMI 1640 , and found that $0.30 \%$ and $0.03 \% \mathrm{H}_{2} \mathrm{O}_{2}$ killed $100 \%$ and $37 \%$ (R6), and $100 \%$ and $100 \%$ (D39), respectively, of those bacteria, whereas $\mathrm{H}_{2} \mathrm{O}_{2}$ killing was nearly completely lost in the presence of erythrocytes (Fig. 5B). These results indicate that $\mathrm{H}_{2} \mathrm{O}_{2}$ killing is inhibited not only by erythrocyte invasion, but also by erythrocyte catalase activity against $\mathrm{H}_{2} \mathrm{O}_{2}$.

\section{Discussion}

Iron is essential for the life of virtually all organisms [12]. However, the present results indicate that $S$. pneumoniae can grow under an iron-depleted condition, which, in contrast, inhibits the growth of $S$. aureus. Ong et al. investigated the growth of $S$. pneumoniae strain D39 in chemically defined medium without iron and that without manganese, and found no significant difference [34]. It is reasonable that $S$. pneumoniae has a low requirement for iron, because this organism lacks a respiratory chain and possesses only a few enzymes that contain iron-sulfur clusters $[34,35,36,37]$. Furthermore, in this study, we showed that iron from intact erythrocytes partially inhibited the growth of $S$. pneumoniae, even though this bacterium is one of the most common Gram-positive pathogens isolated from patients with bloodstream infections [38]. In relation to their physiologic role, human erythrocytes contain abundant oxygen, a potential source of free radicals. Furthermore, erythrocytes are rich in iron ions, which can induce hydroxyl radicals from $\mathrm{H}_{2} \mathrm{O}_{2}$ and/or superoxide anion via Fenton and 


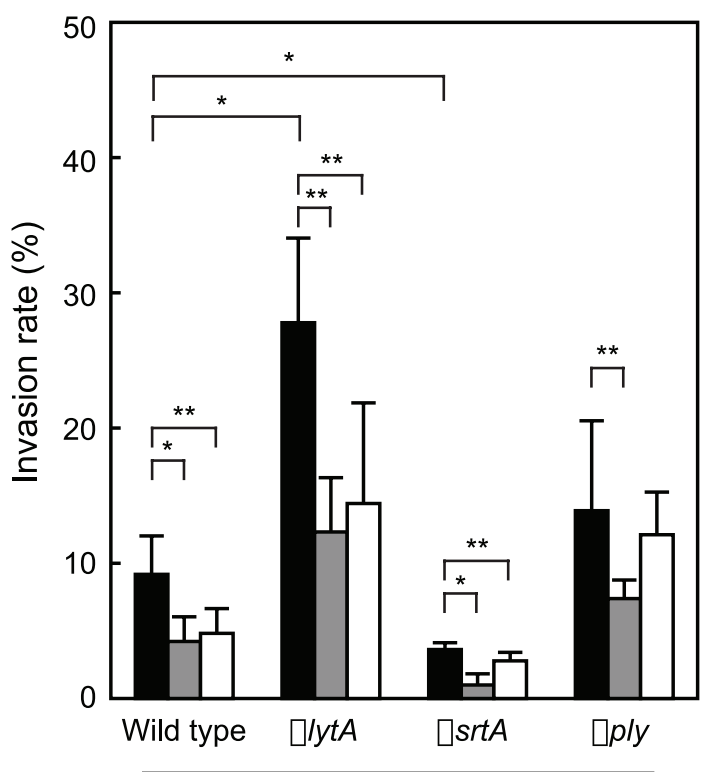

Strain R6

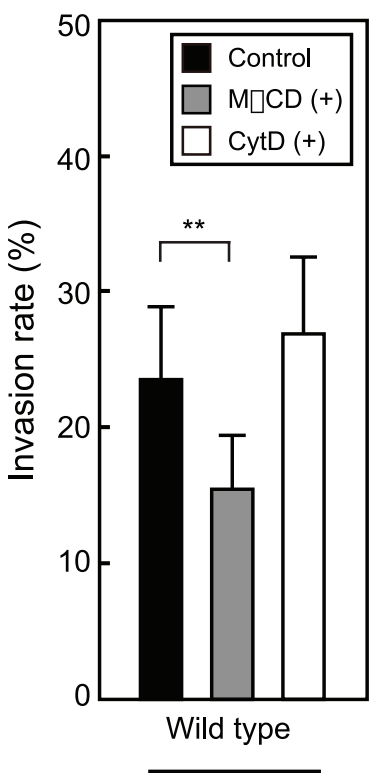

Strain D39

Figure 5. Involvement of lipid rafts and actin remodeling in erythrocyte invasion by S. pneumoniae. Erythrocytes were pretreated with or without $5 \mathrm{mM} \mathrm{M \beta CD}$ or $20 \mu \mathrm{M}$ cytochalasin $\mathrm{D}$ for 30 minutes at $4^{\circ} \mathrm{C}$, then $\mathrm{S}$. pneumoniae cells were added and incubated for 1 hour at $37^{\circ} \mathrm{C}$ in a $5 \%$ $\mathrm{CO}_{2}$ atmosphere. The numbers of invaded bacteria were determined as described in the Experimental Procedures section. The experiments were performed 3 times and data shown represent the mean of 6 wells from a representative experiment. S.D. values are represented by vertical lines. ${ }^{*} P<0.005 ;{ }^{*} P<0.05$.

doi:10.1371/journal.pone.0077282.g005

Harber-Weiss reactions [28]. Although hydroxyl radicals have an extremely short half-life $\left(1 \times 10^{-9}\right.$ seconds at $\left.37^{\circ} \mathrm{C}\right)$, they are highly toxic and cause damage to virtually all types of macromolecules, including DNA, proteins, carbohydrates, and lipids [29,39]. Enzymatic antioxidants such as superoxide dismutase and catalase do not directly eliminate hydroxyl radicals, whereas they are able to eliminate superoxide anion and $\mathrm{H}_{2} \mathrm{O}_{2}$, which are sources of hydroxyl radicals. Thus, hydroxyl radicals may be the main factor involved in growth inhibition of $S$. pneumoniae in the presence of erythrocytes.

Pathogens have been reported to use two different strategies to avoid contact with neutrophils [40]. First, many pathogenic bacteria and fungi are able to inhibit recruitment of neutrophils to the site of infection. For example, lack of neutrophil migration to the site of infection has been frequently noted in severe Streptococcus pyogenes infection cases, as streptococcal proteases degrade interleukin-8, and complements C5a and C3b [40,41]. Second, these pathogenic organisms reside in regions inaccessible to phagocytes. However, it has been observed that many neutrophils are recruited to areas around $S$. pneumoniae organisms. On the other hand, $S$. pneumoniae are able to escape from innate immunity and can spread deep into tissues in cases with severe pneumococcal infections. Thus, we speculated that $S$. pneumoniae has a function to equip itself with molecules or mechanisms to evade neutrophilic immunity. In the present study, we found that $S$. pneumoniae evades antibiotics, neutrophils, and $\mathrm{H}_{2} \mathrm{O}_{2}$ killing in the presence of human erythrocytes. It is generally accepted that invasion of erythrocytes provides bacterial pathogens with a number of advantages, including protection from the immune system, reduction in efficacy of antibiotics treatment, and nutritional benefits. Thus, erythrocytes are considered to provide shelter for $S$. pneumoniae in spite of the disadvantage that iron ions partially reduce bacterial growth. Furthermore, it is possible that this invasion ability is related to the difference between the minimum inhibitory concentration in vitro and that in host blood, because penicillin $\mathrm{G}$ does not kill $S$. pneumoniae organisms after they have invaded erythrocytes.

S. pneumoniae organisms grown in culture broth spontaneously die when reaching the stationary phase, which is a phenomenon dependent on the $s p x B$ gene and its by-product $\mathrm{H}_{2} \mathrm{O}_{2}$ [33]. Interestingly, $\mathrm{H}_{2} \mathrm{O}_{2}$ production by $S$. pneumoniae provides an advantage in competition with other species in vivo [42]. In the present study, $\mathrm{H}_{2} \mathrm{O}_{2}$ killing of $S$. pneumoniae was inhibited in the presence of erythrocytes, suggesting that the pathogen eliminates $\mathrm{H}_{2} \mathrm{O}_{2}$ using catalase present in erythrocytes, which may explain why $S$. pneumoniae organisms lacking catalase show a competitive advantage by producing $\mathrm{H}_{2} \mathrm{O}_{2}$ and carrying the $s p x B$ gene.

$S$. pneumoniae adheres to erythrocytes in a complement- and antibody-dependent process called immune adherence, which enhances its phagocytosis by neutrophils [43,44]. Immune adherence is mediated by the complements C3b, C4b, and C1q, as well as mannose-binding lectin on immune complexes that interact with the CR1 receptor on the surface of erythrocytes [45]. In the present study, $S$. pneumoniae adhered to and invaded erythrocytes in the absence of human serum, while the pathogen evaded neutrophil killing in the presence of human serum and erythrocytes, indicating that erythrocyte invasion by $S$. pneumoniae occurs independent of immune adherence.

In our experiments, we found no significant difference in erythrocyte-invasion between wild-type and $\Delta p l y$ strains of $S$. pneumoniae. Ply attaches to the cell membrane in a cholesteroldependent manner and then oligomerization to form pores on the membrane [46]. At a glance, it seems unusual that bacteria producing cytolysin can also invade erythrocytes. However, $S$. pneumoniae does not destroy host cells through Ply activity when the multiplicity of infection is low. In fact, the pathogen has been reported to invade the human lung epithelial cell line A549 and evade antibiotics killing, while Ply has been shown to cause LDH 
A

Strain R6

$\operatorname{HBS}()$

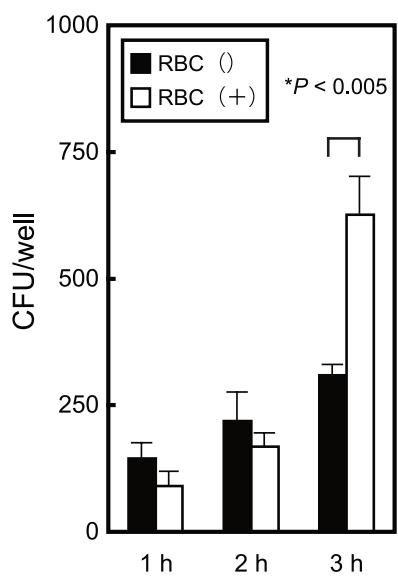

$\operatorname{HBS}(+)$

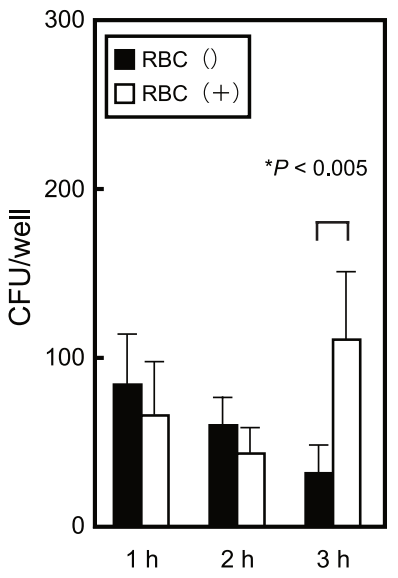

Strain D39

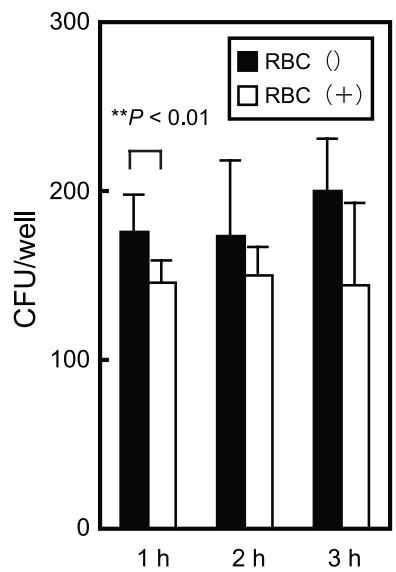

$\operatorname{HBS}(+)$

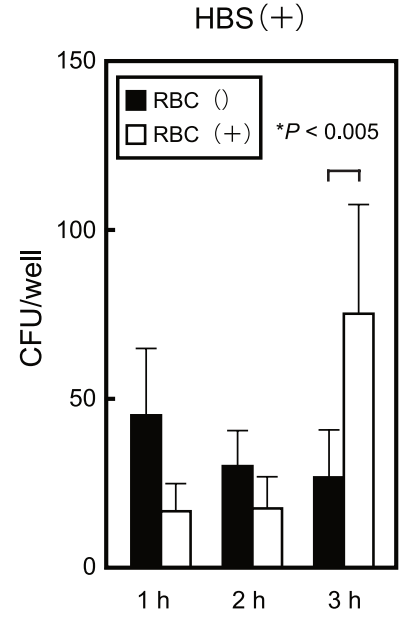

B
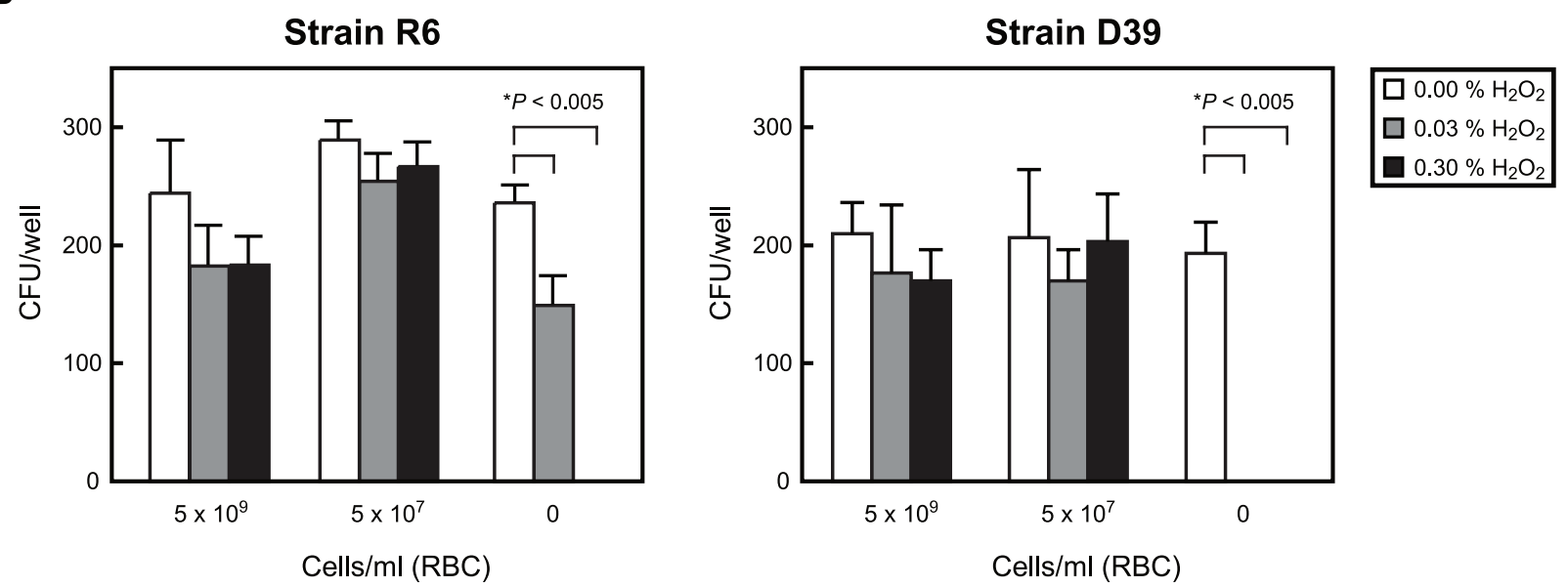

Figure 6. Erythrocytes inhibit killing of $S$. pneumoniae. A. Inhibition of killing by neutrophils. S. pneumoniae cells (R6:2.2 $\times 10^{2} \mathrm{CFU} / \mathrm{well}$, D39:1.4 $\times 10^{2}$ CFU/well) were incubated with human neutrophils $\left(1 \times 10^{5}\right.$ cells/well), then erythrocytes $\left(5.0 \times 10^{7}\right.$ cells/well) and/or $10 \%$ human blood serum (HBS) or heat-inactivated HBS were added to the mixture. Viable CFU were counted following 1,2 , and 3 hours of incubation. $B$. Inhibition of killing by $\mathrm{H}_{2} \mathrm{O}_{2}$. S. pneumoniae cells were incubated in $0 \%, 0.03 \%$, or $0.30 \% \mathrm{H}_{2} \mathrm{O}_{2}-\mathrm{RPMI} 1640$, then viable CFU were counted following 1,2 , and 3 hours of incubation. The experiments were performed 3 times and data shown represent the mean of 6 wells from a representative experiment. S.D. values are represented by vertical lines.

doi:10.1371/journal.pone.0077282.g006

release in cells $[16,47,48]$. Another interesting result is that the $\triangle$ lytA strain showed a 3-fold greater level of invasion as compared to the wild-type strain. One possibility is that the $\Delta l y t A$ strain does not degrade its own cell wall, resulting in a greater number of LPXTG motif-containing proteins remaining on the cell surface to more effectively function as invasion factors as compared to the wild-type strain. Another simple possibility is that LytA and/or degraded peptidoglycan directly inhibit the interaction. Although it has been reported that some Mycoplasma species invade host erythrocytes in animals, the invasion mechanism or pathway remains unclear $[49,50]$. In the present study, we found that $S$. pneumoniae invaded human erythrocytes using a variety of factors, including lipid rafts, actin remodeling, and LPXTG motifcontaining proteins. Therefore, the mechanism of erythrocyte invasion shares some similarities with that of epithelial cell invasion [51,52].

The present findings also demonstrated that human erythrocytes partially inhibit pneumococcal growth by generating ironinduced free radicals. However, S. pneumoniae was found able to invade human erythrocytes and evade innate immunity. Interestingly, though transfusion-transmitted pneumococcal infection caused by erythrocytes has been reported, cultures of blood and swabs from the antecubital fossae, nose, and throat of affected patients were found to be negative for pneumococcal antigens, with urinary testing providing the same results [13]. Thus, it is possible that erythrocytes function as a Trojan horse for the pathogen following pneumococcal invasion. The present novel findings have the potential to cause a paradigm shift in the understanding of sepsis, transfusion transmitted infections, and 
clinical blood test results, as well as the choice of antibiotics in affected patients.

\section{References}

1. van der Poll T, Opal SM (2009) Pathogenesis, treatment, and prevention of pneumococcal pneumonia. Lancet 374: 1543-1556.

2. O'Brien KL, Wolfson LJ, Watt JP, Henkle E, Deloria-Knoll M, et al. (2009) Burden of disease caused by Streptococcus pneumoniae in children younger than 5 years: global estimates. Lancet 374: 893-902.

3. Mitchell AM, Mitchell TJ (2010) Streptococcus pneumoniae: virulence factors and variation. Clin Microbiol Infect 16: 411-418.

4. Kyaw MH, Lynfield R, Schaffner W, Craig AS, Hadler J, et al. (2006) Effect of introduction of the pneumococcal conjugate vaccine on drug-resistant Streptococcus pneumoniae. N Engl J Med 354: 1455-1463.

5. Farrell DJ, Klugman KP, Pichichero M (2007) Increased antimicrobial resistance among nonvaccine serotypes of Streptococcus pneumoniae in the pediatric population after the introduction of 7-valent pneumococcal vaccine in the United States. Pediatr Infect Dis J 26: 123-128.

6. Gertz RE Jr, Li Z, Pimenta FG, Jackson D, Juni BA, et al. (2010) Increased penicillin nonsusceptibility of nonvaccine-serotype invasive pneumococci other than serotypes $19 \mathrm{~A}$ and $6 \mathrm{~A}$ in post-7-valent conjugate vaccine era. J Infect Dis 201: 770-775.

7. Croucher NJ, Harris SR, Fraser C, Quail MA, Burton J, et al. (2011) Rapid pneumococcal evolution in response to clinical interventions. Science 331: 430434.

8. Kadioglu A, Weiser JN, Paton JC, Andrew PW (2008) The role of Streptococcus pneumoniae virulence factors in host respiratory colonization and disease. Nat Rev Microbiol 6: 288-301.

9. Price KE, Camilli A (2009) Pneumolysin localizes to the cell wall of Streptococcus pneumoniae. J Bacteriol 191: 2163-2168.

10. Lopez R, Garcia E (2004) Recent trends on the molecular biology of pneumococcal capsules, lytic enzymes, and bacteriophage. FEMS Microbiol Rev 28: 553-580.

11. Marraffini LA, Dedent AG, Schneewind O (2006) Sortases and the art of anchoring proteins to the envelopes of gram-positive bacteria. Microbiol Mol Biol Rev 70: 192-221.

12. Andrews SC, Robinson AK, Rodriguez-Quinones F (2003) Bacterial iron homeostasis. FEMS Microbiol Rev 27: 215-237.

13. Polizzotto MN, Neo H, Spelman D, Shortt J, Cole-Sinclair MF, et al. (2008) Streptococcus pneumoniae septicemia associated with red blood cell transfusion. Transfusion 48: 1520-1521.

14. Yamaguchi M, Minamide Y, Terao Y, Isoda R, Ogawa T, et al. (2009) Nrc of Streptococcus pneumoniae suppresses capsule expression and enhances antiphagocytosis. Biochem Biophys Res Commun 390: 155-160.

15. Mori Y, Yamaguchi M, Terao Y, Hamada S, Ooshima T, et al. (2012) alphaEnolase of Streptococcus pneumoniae induces formation of neutrophil extracellular traps. J Biol Chem 287: 10472-10481.

16. Yamaguchi M, Terao Y, Mori Y, Hamada S, Kawabata S (2008) PfbA, a novel plasmin- and fibronectin-binding protein of Streptococcus pneumoniae, contributes to fibronectin-dependent adhesion and antiphagocytosis. J Biol Chem 283: 3627236279 .

17. Eggleton P, Gargan R, Fisher D (1989) Rapid method for the isolation of neutrophils in high yield without the use of dextran or density gradient polymers. J Immunol Methods 121: 105-113.

18. Pishchany G, McCoy AL, Torres VJ, Krause JC, Crowe JE Jr, et al. (2010) Specificity for human hemoglobin enhances Staphylococcus aureus infection. Cell Host Microbe 8: 544-550.

19. Garvey EP, Oplinger JA, Tanoury GJ, Sherman PA, Fowler M, et al. (1994) Potent and selective inhibition of human nitric oxide synthases. Inhibition by non-amino acid isothioureas. J Biol Chem 269: 26669-26676.

20. Pucheu S, Boucher F, Sulpice T, Tresallet N, Bonhomme Y, et al. (1996) EUK-8 a synthetic catalytic scavenger of reactive oxygen species protects isolated ironoverloaded rat heart from functional and structural damage induced by ischemia/reperfusion. Cardiovasc Drugs Ther 10: 331-339.

21. Zhao H, Joseph J, Fales HM, Sokoloski EA, Levine RL, et al. (2005) Detection and characterization of the product of hydroethidine and intracellular superoxide by HPLC and limitations of fluorescence. Proc Natl Acad Sci U S A 102: 5727-5732.

22. Fallarino F, Bianchi R, Orabona C, Vacca C, Belladonna ML, et al. (2004) CTLA-4-Ig activates forkhead transcription factors and protects dendritic cells from oxidative stress in nonobese diabetic mice. J Exp Med 200: 1051-1062.

23. Yamaguchi M, Terao Y, Ogawa T, Takahashi T, Hamada S, et al. (2006) Role of Streptococcus sanguinis sortase A in bacterial colonization. Microbes Infect 8: 2791-2796.

24. Rohde M, Muller E, Chhatwal GS, Talay SR (2003) Host cell caveolae act as an entry-port for group A streptococci. Cell Microbiol 5: 323-342.

25. Lafont F, van der Goot FG (2005) Bacterial invasion via lipid rafts. Cell Microbiol 7: 613-620.

\section{Author Contributions}

Conceived and designed the experiments: MY KN AY SK. Performed the experiments: MY YT YMY HD YS TY. Analyzed the data: MY YT KN AY SK. Contributed reagents/materials/analysis tools: MY YT TY VN. Wrote the paper: MY YT VN SK.

26. Skaar EP, Humayun M, Bae T, DeBord KL, Schneewind O (2004) Iron-source preference of Staphylococcus aureus infections. Science 305: 1626-1628.

27. Doherty CP (2007) Host-pathogen interactions: the role of iron. J Nutr 137: 1341-1344.

28. Cimen MY (2008) Free radical metabolism in human erythrocytes. Clin Chim Acta 390: 1-11.

29. Reiter RJ, Melchiorri D, Sewerynek E, Poeggeler B, Barlow-Walden L, et al. (1995) A review of the evidence supporting melatonin's role as an antioxidant. J Pineal Res 18: 1-11.

30. Henderson B, Nair S, Pallas J, Williams MA (2011) Fibronectin: a multidomain host adhesin targeted by bacterial fibronectin-binding proteins. FEMS Microbiol Rev 35: 147-200.

31. Iliev AI, Djannatian JR, Nau R, Mitchell TJ, Wouters FS (2007) Cholesteroldependent actin remodeling via RhoA and Racl activation by the Streptococcus pneumoniae toxin pneumolysin. Proc Natl Acad Sci U S A 104: 2897-2902.

32. Vieira FS, Correa G, Einicker-Lamas M, Coutinho-Silva R (2010) Host-cell lipid rafts: a safe door for micro-organisms? Biol Cell 102: 391-407.

33. Regev-Yochay G, Trzcinski K, Thompson CM, Lipsitch M, Malley R (2007) $\mathrm{SpxB}$ is a suicide gene of Streptococcus pneumoniae and confers a selective advantage in an in vivo competitive colonization model. J Bacteriol 189: 6532-6539.

34. Ong CL, Potter AJ, Trappetti C, Walker MJ, Jennings MP, et al. (2013) Interplay between manganese and iron in pneumococcal pathogenesis: role of the orphan response regulator RitR. Infect Immun 81: 421-429.

35. Hoskins J, Alborn WE Jr, Arnold J, Blaszczak LC, Burgett S, et al. (2001) Genome of the bacterium Streptococcus pneumoniae strain R6. J Bacteriol 183: 5709-5717.

36. Lanie JA, Ng WL, Kazmierczak KM, Andrzejewski TM, Davidsen TM, et al. (2007) Genome sequence of Avery's virulent serotype 2 strain D39 of Streptococcus pneumoniae and comparison with that of unencapsulated laboratory strain R6. J Bacteriol 189: 38-51.

37. Tseng HJ, McEwan AG, Paton JC, Jennings MP (2002) Virulence of Streptococcus pneumoniae: PsaA mutants are hypersensitive to oxidative stress. Infect Immun 70: 1635-1639.

38. van der Poll T, Opal SM (2008) Host-pathogen interactions in sepsis. Lancet Infect Dis 8: $32-43$.

39. Sies H (1993) Strategies of antioxidant defense. Eur J Biochem 215: 213-219.

40. Urban CF, Lourido S, Zychlinsky A (2006) How do microbes evade neutrophil killing? Cell Microbiol 8: 1687-1696.

41. Terao Y, Mori Y, Yamaguchi M, Shimizu Y, Ooe K, et al. (2008) Group A streptococcal cysteine protease degrades $\mathrm{C} 3(\mathrm{C} 3 \mathrm{~b})$ and contributes to evasion of innate immunity. J Biol Chem 283: 6253-6260.

42. Regev-Yochay G, Trzcinski K, Thompson CM, Malley R, Lipsitch M (2006) Interference between Streptococcus pneumoniae and Staphylococcus aureus: In vitro hydrogen peroxide-mediated killing by Streptococcus pneumoniae. J Bacteriol 188: 4996-5001.

43. Hament JM, van Dijk H, Fleer A, Aerts PC, Schoenmakers M, et al. (2003) Pneumococcal immune adherence to human erythrocytes. Eur J Clin Invest 33: 169-175.

44. Li J, Wang JP, Ghiran I, Cerny A, Szalai AJ, et al. (2010) Complement receptor 1 expression on mouse erythrocytes mediates clearance of Streptococcus pneumoniae by immune adherence. Infect Immun 78: 3129-3135.

45. Tas SW, Klickstein LB, Barbashov SF, Nicholson-Weller A (1999) C1q and C4b bind simultaneously to CR1 and additively support erythrocyte adhesion. J Immunol 163: 5056-5063.

46. Marriott HM, Mitchell TJ, Dockrell DH (2008) Pneumolysin: a double-edged sword during the host-pathogen interaction. Curr Mol Med 8: 497-509.

47. Hirst RA, Yesilkaya H, Glitheroe E, Rutman A, Dufty N, et al. (2002) Sensitivities of human monocytes and epithelial cells to pneumolysin are different. Infect Immun 70: 1017-1022.

48. Holmes AR, McNab R, Millsap KW, Rohde M, Hammerschmidt S, et al. (2001) The pavA gene of Streptococcus pneumoniae encodes a fibronectin-binding protein that is essential for virulence. Mol Microbiol 41: 1395-1408.

49. Vogl G, Plaickner A, Szathmary S, Stipkovits L, Rosengarten R, et al. (2008) Mycoplasma gallisepticum invades chicken erythrocytes during infection. Infect Immun 76: 71-77.

50. Groebel K, Hoelzle K, Wittenbrink MM, Ziegler U, Hoelzle LE (2009) Mycoplasma suis invades porcine erythrocytes. Infect Immun 77: 576-584.

51. Yamaguchi M, Terao Y, Kawabata S (2013) Pleiotropic virulence factor Streptococcus pyogenes fibronectin-binding proteins. Cell Microbiol 15: 503-511.

52. Lofling J, Vimberg V, Battig P, Henriques-Normark B (2011) Cellular interactions by LPxTG-anchored pneumococcal adhesins and their streptococcal homologues. Cell Microbiol 13: 186-197. 